\title{
The Relationship Between Professional Job Burnout and Temperament (Mizaj) from the Viewpoint of Traditional Persian Medicine and Work-Related Variables Among Iranian Dentists: A Cross- Sectional Study
}

fereshteh noori

Shaid Sadoughi university of medical science, Yazd. Iran

fatemeh owlia ( $\Delta$ dr.owlia@gmail.com )

Shaid Sadoughi university of medical science, Yazd. Iran seyed kazem kazemeini

Shaid Sadoughi university of medical science, Yazd. Iran

\section{Research Article}

Keywords: Burnout, Maslach Burnout Inventory, Temperament, Dentists, Persian medicine

Posted Date: August 4th, 2021

DOl: https://doi.org/10.21203/rs.3.rs-761596/v1

License: (1) (i) This work is licensed under a Creative Commons Attribution 4.0 International License. Read Full License 


\section{Abstract}

background: Dentists are prone to professional burnout due to the nature of their work but this phenomenon may be prevented. Professional burnout has a great impact on different aspects of human life. On the other hand, temperament could have a vital role in behaviors, interests, and lifestyle. The present study aimed to determine the professional burnout level among Iranian dentists and its association with temperament in view of traditional Persian medicine and work-related variables.

Methods: This observational study with a cross-sectional design was conducted among an Iranian dentist sample in Yazd between February 2020 and August 2020. 145 dentists were enrolled in the study. Human temperament and burnout levels were assessed by means of the Salmannejad temperament and Maslach Burnout Inventory questionnaires (MBI), respectively.

In total, 120 valid questionnaires were collected, with a response rate of $82.76 \%$. Data analysis was performed using descriptive statistics mean and standard deviation, Analytical tests (including chi-square test, multivariate analysis of variance) using Spss17 (Chicago, USA) software was done.

Results: Among participants, $8.3 \%$ had high emotional exhaustion, $7.5 \%$ had depersonalization and $2.5 \%$ had reduced personal accomplishment. According to the results, $28.3 \%$ of dentists had warm-wet, $13.3 \%$ had warm-dry, $7.5 \%$ had cold-dry and $13.3 \%$ had cold-wet mizaj. The score of professional burnout in the area of emotional exhaustion had a positive correlation with job satisfaction. (P-value<0.05)

Conclusion: Based on the findings, it is concluded, it may conclude professional burnout and job satisfaction had a negative significant correlation. No statistically significant relationship was seen between different mizaj and professional burnout among dentists.

\section{Background}

Burnout is a workplace problem due to practice in an institute with conflict of multiple objectives[1]. It is a process of physical and mental exhustion caused by constant and successive emotional stress due to long-term conflict in humans[2]. In fact, it is a continuous response to chronic personal and emotional pressures in the workplace that can occur under conditions of severe job stress[3, 4]. Maslach et al. were among the first researchers to describe this concept. They described burnout as a syndrome that includes three dimensions: emotional exhustion, depersonalization, and reduced personal accomplishment[5]. Emotional exhustion is the key to measuring burnout and is a response to stress that results from an increase in negative job trends and a loss of interest in people. Depersonalization is a cruel and indifferent response to service recipients. This dimension of burnout is very important for jobs with human services. Reduced personal accomplishment is a negative self-assessment during work, feeling of worthless[6]. Burnout reduces the interest, emotions and level of performance of people and its effects may be appeared in the form of physical symptoms such as headaches and indigestion, psychological symptoms such as depression and anger and behavioral symptoms such as loss of work and absence[2]. Studies showed that dentists encounter various professional stressful situations. Job pressures in 
dentistry are relatively high. Prolonged sitting on the chair, great precision while the eyes are focused on distinct point and fine movements of the fingers, as well as the management of the environment and the office are known as the main causes of stress among dentists[7]. Evidence suggests that about $13 \%$ of dentists experience high levels of burnout[6]. Stress accumulation accelerates burnout. In addition, there is some evidences affirmed, burnout in dentists has a negative impact on patients' health[8]. Patients will have less satisfaction in confronting health care workers with professional burnout [9]. Therefore, it is necessary to study the dimensions of burnout and related factors[10]. Of course, this study is the first to examine this issue from the perspective of traditional medicine. In spite of neglecting traditional Persian medicine in past decades, nowadays it would be recognized as the first line of treatment in various diseases[11]. Temperament (mizaj) is the turning point of physiopathology of diseases that is the result of the influence of the qualities of the four elements, namely warmth, coldness, dryness and wet on each other. In medicine mizaj means the innate power in the body that could controls all aspects of the body [12]. This theory of medicine is based on 4 main mizaj composed of biliary temperament (hot and dry), sanguine (warm and wet), phlegmatic (cold and wet) and choleric (cold and dry)[13]. According to the theories of traditional persian medicine, moods and mental status depend on their temperament, therefore, it can be found that behaviors and tendencies are influenced by different mizaj $[14,15]$.In traditional persian medicine, many health instructions related to lifestyle and health measures are based on people's mizaj. Mizaj is the quality that results from the action and reaction between the contrasting qualities of the elements. when the opposite characteristics is balanced the definite mizaj is appeared[16]. From the viewpoint of traditional Persian medicine, everyone has their own temperament. People can be warmer, colder, drier or wetter than balanced. Since the formation of the medical mood is a subtle part of the mixed natures, it is clear that the dominance of a particular temperaments involves not only physical characteristics but also moral characteristics. Temperament also affects moods, interests and even fertility power[17]. In comparison with other jobs, dentistry is a stressful job. Many studies have been conducted on the history of burnout in dentists $[10,18,19]$.

Choy et al. determined burnout level and occupational stress in Hong Kong dentists. They showed that $25.4 \%$ had high levels of emotional exhustion, $17.2 \%$ had high levels of depersonalization and $39 \%$ of the subjects had high levels of reduced personal accomplishment[19]. Basirat et al. investigated burnout level and the associated factors in dentists in Semnan province. According to their results, $40.7 \%$ suffered from high emotional exhustion, $22.1 \%$ had severe depersonalization and $97.7 \%$ exprienced severe reduced personal accomplishment[20]. Banai et al. in 2017 reported the meaningful relationship between temperament and communication skills in nursing and midwifery students. Regarding to the study students with hot and wet temperaments as well as hot and dry temperaments had higher communication skills than students with cold and wet temperaments and cold and dry temperaments[15]. Considering no study has been done on the relationship between professional burnout and temperament, the novelty of present study is determining the professional burnout level among Iranian dentists and its relationship with mizaj in viewpoint of traditional Persian medicine and workrelated variables. 


\section{Methods}

This was an observational study with a cross-sectional design. The survey was conducted in February 2020-August 2020. According to the study design, 145 randomly selected dentists entered to the study. First the data were collected from dentists who were selected based on random number table regarding to the list of Yazd medical council. The relationship between professional burnout level and different mizaj was evaluated by two valid questionnaires of Maslach Burnout Inventory questionnaires (MBI) and Salmannejad temperament questionnaire [21,22]. The license to use both questionnaires among the required number of respondents was purchased from the copyright holder. The Persian version of $\mathrm{MBI}$ stionnaire were filled out by participants. It should be noted that there was no time limit for completing the questionnaire and therefore, it was tried to distribute and collect the questionnaires away from work and in a suitable situation.

A total of 120 valid questionnaires were collected with the response rate of $82.76 \%$. Because 25 responders did not answer all questions of both questionaires, they were excluded, therefore the final study sample comprised of 120 dentists. The data collection conformed to the princioles that were obtained in the World Medical Association's Declaration of Helsinki. It was approved by the "Ethics Committee in Research of Shahid Sadoughi University of Medical Sciences, Yazd" under the number IR.SSU.REC.1398.192.

The level of professional burnout, the MBI questionnaire with Cronbach's alpha coefficient of 0.75 was used. It had 22 items self reported questions. 9, 5 and 8 questions were related to emotional exhustion, depersonalization and reduced personal accomplishment, respectively. Each question expressed the level of burnout with limited range from zero (never) to 6 (always). The score obtained in each domain was divided into three categories: low, medium and severe[21]. Salman-Nejad mizaj identification questionnaire contained 20 items that evaluate two categories of warmness/coldness and dry/ wet nature. The subjects rated their responses on $0-5$ scale. It is the first standard mizaj identification questionnaire. It is a reliable and validate questionnaire with Cronbach's alpha coefficient equal to 0.77$0.80[22]$.

The participantts were in the age range of 28 to 60 years and had at least 2 years of work experience. Information regarding the participants including age, sex, and other demogrophic characteristics was also collected. Because this study was focused on job-related issues, the checklist included questions on work practice experience, employment status, number of working days per week, number of patients per day, type of income and job selection or avoidance. After explaining the purpose of the survey and the confidentiality of the information, participants completed the questionnaires. All of them signed the written consent letter.

A very detailed history of systemic diseases, taking medication and physical disability was taken. Dentists with propable diagnosis of neuropsychiatric or neuromuscular diseases or taking related drugs 
or corticosteroids did not enter to the study. All of them filled the HADS questionnaire for detecting symptoms of anxiety and depression.

All of the analyses were conducted at $p<0.05$ level of significance using SPSS statistical package (version 21.0; SPSS Inc., Chicago, IL, USA; 2012). Descriptive statistics (frequency, mean, and standard deviation), and analytical statistics (including chi-square test, multivariate analysis of variance). Then, the relationship between different temperaments and burnout level was measured by Pearson correlation coefficient.

\section{Results}

$55 \%$ of participants were male and $45 \%$ were female. The mean age \pm SD of the samples was $35.2 \pm 7.2$ with a range of 28 to 60 years. Data analysis showed that $66.7 \%$ of dentists had low emotional exhustion, $65.8 \%$ had moderate depersonalization and $64.3 \%$ had a low reduced personal accomplishment (Table 1).

Table 1

burnout level of dentists based on MBI scales

\begin{tabular}{|llll|}
\hline Maslach burnout dimensions & high & medium & low \\
\cline { 2 - 4 } & Number(percent) & Number(percent) & Number(percent) \\
\hline Emotional exhaustion & $10(8.3 \%)$ & $30(25.0 \%)$ & $80(66.7 \%)$ \\
\hline depersonalization & $9(7.5 \%)$ & $79(65.8 \%)$ & $32(26.7 \%)$ \\
\hline Reduced personal accomplishment & $3(2.5 \%)$ & $40(33.3 \%)$ & $77(64.2 \%)$ \\
\hline
\end{tabular}

Based on the obtained results, the frequency of 4 main mizaj was as followed: $28.3 \%$ hot and wet, $13.3 \%$ cold and wet, $13.3 \%$ hot and dry and $7 \%$ had a cold and dry. The highest frequency of mizaj was related to warm and wet and the lowest frequency was atributed to temperate-temperate. According to pvalue > 0.05 , there was no significant difference between temperaments among dentists (Table 2). 
Table 2

Frequency of different mizaj in dentists

\begin{tabular}{|llll|}
\hline Types of temperaments & Number(percent) & man & woman \\
\hline Warm and wet & $34(28.3 \%)$ & 21 & 13 \\
\hline Warm and dry & $16(13.3 \%)$ & 9 & 7 \\
\hline Cold and dry & $9(7.5 \%)$ & 3 & 6 \\
\hline Cold and wet & $16(13.3 \%)$ & 10 & 6 \\
\hline Warm and temperate & $9(7.5 \%)$ & 4 & 5 \\
\hline cold and temperate & $10(8.3 \%)$ & 5 & 5 \\
\hline Temperate and dry & $9(7.5 \%)$ & 5 & 4 \\
\hline Temperate and wet & $14(11.6 \%)$ & 9 & 5 \\
\hline Temperate and Temperate & $3(2.5 \%)$ & 0 & 3 \\
\hline total & $120(100 \%)$ & 66 & 54 \\
\hline
\end{tabular}

ANOVA

The study illustrated that people with cold and dry temperament had higher level of burnout in emotional exhustion while dentists with warm and wet temperament had higher level of burnout in depersonalization and reduced personal accomplishment dimensions. But this difference between the four temperaments was not statistically significant (Table 3 ).

Table 3

Comparison of Professional burnout in different mizaj in dentists

\begin{tabular}{|lllll|}
\hline $\begin{array}{l}\text { different } \\
\text { mizaj }\end{array}$ & number & Emotional exhaustion & depersonalization & Personal accomplishment \\
\hline Warm and wet & 34 & $11.83 \pm 14.70$ & $3.03 \pm 7.58$ & $5.41 \pm 30.88$ \\
\hline Warm and dry & 16 & $6.08 \pm 8.37$ & $2.92 \pm 6.56$ & $6.90 \pm 30.81$ \\
\hline Cold and dry & 9 & $9.62 \pm 16.77$ & $2.26 \pm 7.11$ & $4.31 \pm 30.11$ \\
\hline Cold and wet & 16 & $10.64 \pm 14.06$ & $2.27 \pm 6.87$ & $5.04 \pm 28.87$ \\
\hline p-value & & 0.60 & 0.90 & 0.93 \\
\hline
\end{tabular}

ANOVA

Table 4 indicates the average rate of burnout in dentists based on sex and work-related variables. Both genders conveyed the similar burnout level in reduced personal accomplishment, emotional exhustion and depersonalization, respectively. Although the burnout level was higher in men, but these values were not statistically significant. On the other hand, with increasing the number of patients per day and the number of working days per week, although the rate of burnout increased, but there was no significant 
relationship between age, sex, work experience, number of working days per week, number of patients per day with the dimensions of burnout. The average burnout in emotional exhustion dimension was significantly higher in dentists with avoidance job rather than in those with selective job ( $p$ value $=0.01)$ (Table 4).

Table 4

Comparison of Professional burnout in different mizaj according to the studied variables

\begin{tabular}{|c|c|c|c|c|c|}
\hline variables & & $\begin{array}{l}\text { Number } \\
\text { (\%) }\end{array}$ & $\begin{array}{l}\text { Emotional } \\
\text { exhaustion } \\
\text { means } \pm \\
\text { standard } \\
\text { deviation }\end{array}$ & $\begin{array}{l}\text { depersonalization } \\
\text { mean } \pm \text { standard } \\
\text { deviation }\end{array}$ & $\begin{array}{l}\text { Reduced personal } \\
\text { accomplishment } \\
\text { means } \pm \text { standard } \\
\text { deviation }\end{array}$ \\
\hline \multirow{3}{*}{$\begin{array}{l}\text { Age } \\
\text { groups }\end{array}$} & $28-34$ & $69(57.5 \%)$ & $11.18 \pm 13.73$ & $2.91 \pm 27.7$ & $5.6 \pm 30.18$ \\
\hline & $35-60$ & $51(42.5 \%)$ & $8.92 \pm 13.45$ & $2.35 \pm 6.96$ & $4.85 \pm 29.88$ \\
\hline & $p$-value* & & 0.88 & 0.52 & 0.75 \\
\hline \multirow[t]{3}{*}{ sex } & female & $54(45 \%)$ & $9.96 \pm 13.51$ & $2.40 \pm 6.77$ & $5.36 \pm 29.25$ \\
\hline & male & $66(55 \%)$ & $10.55 \pm 13.69$ & $2.88 \pm 7.43$ & $5.15 \pm 30.71$ \\
\hline & $p$-value* & & 0.92 & 0.18 & 0.13 \\
\hline \multirow{3}{*}{$\begin{array}{l}\text { Working } \\
\text { experience } \\
\text { (year) }\end{array}$} & $2-6$ & $61(50.8 \%)$ & $11.71 \pm 14.39$ & $2.84 \pm 7.36$ & $4.92 \pm 30.55$ \\
\hline & $7-36$ & $59(49.1 \%)$ & $8.49 \pm 12.81$ & $2.52 \pm 6.91$ & $5.61 \pm 29.54$ \\
\hline & p-value* & & 0.40 & 0.36 & 0.29 \\
\hline \multirow{3}{*}{$\begin{array}{l}\text { Working } \\
\text { days per } \\
\text { week }\end{array}$} & $1-4$ days & $52(43.3 \%)$ & $10.30 \pm 12.77$ & $2.09 \pm 7.09$ & $5.24 \pm 30.49$ \\
\hline & $5 \leq$ days & $67(55.8 \%)$ & $10.23 \pm 14.28$ & $3.09 \pm 7.17$ & $5.31 \pm 29.71$ \\
\hline & p-value* & & 0.42 & 0.86 & 0.42 \\
\hline \multirow[t]{3}{*}{$\begin{array}{l}\text { Patients } \\
\text { per day }\end{array}$} & $\begin{array}{l}3-4 \\
\text { patients }\end{array}$ & $25(20.8 \%)$ & $9.62 \pm 13.32$ & $3.04 \pm 7.04$ & $4.08 \pm 31.60$ \\
\hline & $\begin{array}{l}5 \leq \\
\text { patients }\end{array}$ & $95(79.1 \%)$ & $10.45 \pm 13.69$ & $2.60 \pm 7.16$ & $5.27 \pm 29.65$ \\
\hline & p-value* & & 0.87 & 0.83 & 0.10 \\
\hline \multirow{3}{*}{$\begin{array}{l}\text { Voluntary } \\
\text { or } \\
\text { involuntary } \\
\text { job }\end{array}$} & voluntary & $94(78.3 \%)$ & $10.07 \pm 12.43$ & $2.68 \pm 7.05$ & $4.95 \pm 30.19$ \\
\hline & involuntary & $26(21.6 \%)$ & $9.90 \pm 17.88$ & $2.71 \pm 7.46$ & $6.39 \pm 29.57$ \\
\hline & p-value* & & $0.01 *$ & 0.49 & 0.60 \\
\hline
\end{tabular}

Pearson chi-square 


\section{Discussion}

Different cultural factors, having different socio-economic levels on dentists' burnout, are effective. Professional burnout can significantly impact on dentists' mood and professional health and the quality of their dental services [23]. The aim of this study was to determine the level of burnout among Iranian dentists and its relationship with temperament in terms of traditional medicine and work-related variables variables. The findings showed that in terms of the dimensions of burnout, the areas of emotional exhustion and reduced personal accomplishment were at the lower level, in other words, near to half of the participants had low level of burnout. Awareness of personal characteristics by determination of the temperament effectively facilitates job selection process and improve their assumption related to the job. As a result, burnout will be reduced[24]. According to the results of the present study, $8.3 \%$ showed a high rate of burnout in emotional exhustion, $7.5 \%$ in depersonalization, and $2.5 \%$ in reduced personal accomplishment dimensions. Many of participants exprienced low level of emotional exhaustion and reduced personal accomplishment and moderate depersonalization. The findings of this survey go in line with the study of Eslamipour et al., which was performed on dentists in Isfahan. Both studies reported the participants had low emotional exhustion and reduced personal accomplishment. This issue may be justified by the cultural similarity of the two Iranian societies[3]. Basirat et al concluded a different result. They were reported reduced personal accomplishment had the first place in ranking of professional burnout dimensions[20]. The difference between the results of similar studies can be related to the discrepancy in smple size, socioeconomic conditions and various personal characteristics. It is interpreted as "mizaj" in view of traditional Persian medicine. Results showed that there was not a significant relationship between none of dimensions of professional burnout and age of the subjects ( $p>0.05)$. It was consistent with the results of Jaracz et al., Porto et al $[25,26]$. However, other literatures mentioned a significant and inverse relationship between age of individuals with the frequency of depersonalization and decreased personal success[3,27]. Regarding the mean age groups of the present study people aged 28 to 34 years had higher level of burnout in reduced personal accomplishment and emotional exhaustion dimentions while people aged 30 to 65 years, the oldest age group, showed the lower level of burnout in all dimensions than the younger group. It was confirmed the findings of Shrofi et al' study[28]. This point could be justified, having more working experience and professional skills with aging could lead to lower level of stress of failure of the dental treatment and feeling more selfconfidence. Over time, dentists become more adaptable to the work environment, which reduces the various areas of burnout. Although no significant relationship was found between sex and burnout, the average dimensions of burnout in women were lower than men. It was consistent with the results of studies by jaracz et al[25]. However, the study of Eslamipour et al. showed that the frequency and severity of emotional exhustion and depersonalization were significantly higher in men[3].

Most of literatures determined the insignificance between two genders, it seems that this issue is more related to masculine temperament in female employees, this characteristic will be reinforced in dentistry especially noticeable in general dentists. Perhaps a different result would be obtained if this study were conducted in specialized disciplines such as pediatric dentists. This field deal with subtle feminine 
moods and more noticeable sex differences[29]. However, our result dedicated dentists with 2 to 6 years of work experience had more burnout than dentists with 7 to 36 years of experience, but there was no significant correlation between the work experience of dentists and burnout. In explaining these results, it can be inferred that with aging, the degree of adaptation to the job would be increased. In other words, job satisfication is propable after more working experience. Therefore, less level of burnout would be occurred. This point was affirmed by Porto et al. and Jaracz et al. They found no significant relationship between work experience and burnout [25, 26]. But Basirat et al., mentioned the direct relationship between work experience and dimensions of emotional exhustion and reduced personal accomplishment. They showed higher rate of work experience lead to depersonalization reduction and more accomplishment[20]. The lack of a significant relationship between the dimensions of burnout and workrelated variables such as working days per week, number of patients per day and work experience indicates that measurement of all three variables is not required in future studies. It could be suggested all of the above-mentioned vaiables could be considered as working load. Finding showed a significant relationship between the selective or avoidance job and emotional exhustion. It means the dentists whose job was avoidance had more emotional exhustion and depersonalization. It may be concluded if there is job satisfaction and person choose his profession, he will have exprienced less professional burnout [30]. Unfortunately, in Iran, there is no published article about mizaj and burnout among dentists. The novelty of this study was a new approach from the perspective of traditional Persian medicine to evaluate the relationship between burnout and mizaj. Attention to this point could have a significant impact on job satisfaction. These finding was compared with similar studies which evaluated different personality types with burnout[31, 32].

Regarding the past literatures, the correlation between job satisfaction and different dimensions of burnout was negative and significant $[33,34]$. Dehghanan et al. determined the effect of different mizaj on job satisfaction of employees. They deducted the coefficients of warmth, coldness and dry and wet temperaments on job satisfaction were significant[35]. Another study also found a positive association between psychological character type and burnout[36]. Many articles have been published in the field of mizaj, but so far none of them have examined its relationship with burnout[37, 38]. According to past studies, it was found that burnout may be occur as a result of a person's mood, which has been measured in different interpretations in studies. Personality types and temperament were the topics of related studies. This study is unique in terms of innovation in the subject. Findings of this study can be applied to conduct more extensive studies in future. Lifestyle modification regarding traditional Persian medicine can be helpful for preventing or minimizing propable burnout.

\section{Limitations}

Our study has some limitations to be considered. First, it is vital to be aware of the predictive limitations of cross-sectional studies by limited multiple regression analysis. Causal relationships can be clarified by carrying out additional prospective research. However, the authors understood that this work has an exploratory objective, and the results should be confirmed with further studies with more participants. 
Despite of negative effect of burnout on job performance, family and personal role, absenteeism from work and early retirement due to burnout should not be neglected. It is possible to minimize stressors by carefully considering the people's mizaj before enterance to job positions. It would be suggested that at the time of job selection, people should be decided away from stress to suffer less burnout in future.

\section{Conclusion}

Based on the findings, it is concluded the dentists experienced low professional burnout in emotional exhaustion and reduced personal accomolishment dimensions. There is no statistically significant different between burnout and various mizaj. The significance of the variable of avoidance or voluntary employment showed that a dentist with acceptable job satisfaction, whether female or male, with each workload will exprience less professional burnout during working life.

\section{Declarations}

\section{Acknowledgment}

We would like to thank the Vice Chancellor for Technology Research of Shahid Sadoughi University of Medical Sciences in Yazd for approving and financially supporting the project with the code 6481.

\section{Authors' contributions}

FO and SKK designed the study, FN contributed to data collection and had critical feedback on the manuscript. FO, SKK and FN assisted in the prepare data for analysis and data analysis, writing and critically reviewing multiple manuscript drafts. All authors contributed to the manuscript revision, read and approved the submitted version.

\section{Funding}

The Vice Chancellor for Research and Technology of Yazd Shahid Sadoughi University of Medical Sciences. (Grant no 6481).

\section{Availability of data and materials}

The datasets analyzed during the current study are available from the corresponding author on reasonable request.

\section{Ethics approval and consent to participate}


Data were collected after obtaining written informed consent from all of the participants. This research project was approved by the Ethics Committee of Yazd Shahid Sadoughi University of Medical Sciences, Yazd, Iran. (IR.SSU.REC.1398.192)

\section{Consent for publication}

Not applicable.

\section{Competing interests}

There is no conflict of interest to be declared.

\section{Author details}

1 dentistry student, School of Dentistry, Shahid Sadoughi University of Medical Sciences, Yazd, Iran.2 *Department of Oral and maxillofacial Medicine, School of Dentistry, Shahid Sadoughi University of Medical Sciences, Yazd, Iran. 3 *Social determinants of oral health research center, shahid Sadoughi university of medical sciences, Yazd, Iran.4 specialist of traditional Persian medicine, Shahid Sadoughi University of Medical University, Yazd, Iran

\section{References}

1. Chemali Z, Ezzeddine F, Gelaye B, Dossett M, Salameh J, Bizri M, Dubale B, Fricchione G: Burnout among healthcare providers in the complex environment of the Middle East: a systematic review. BMC public health 2019, 19(1):1-21.

2. Toubaei S, Daghighafkar M, Haghshenas H: The Relation of Dentists Job Burnout with their General Health, Demographic and Personality Characteristics. Journal of Dentistry 2009, 10(4):348-355.

3. ESLAMIPOUR F, YAZDCHI E: OCCUPATIONAL BURNOUT AMONG DENTISTS IN ISFAHAN. JOURNAL OF ISFAHAN DENTAL SCHOOL 2017, 12(4):-.

4. Soltaniyan MA, Aminbeidokhti AA: The role of sport on job burnout of employees. Koomesh journal 2009, 10(4):281-286.

5. SADEGHI A, SHADI M, MOGHIMBAEIGI A: RELATIONSHIP BETWEEN NURSES' JOB SATISFACTION AND BURNOUT. AVICENNA JOURNAL OF NURSING AND MIDWIFERY CARE (SCIENTIFIC JOURNAL OF HAMADAN NURSING \& MIDWIFERY FACULTY) 2017, 24(4):-

6. Roghanizad N, Vatanpoor M, Seddigh Oraee SN, Sharifi V, Abbasi M: Prevalence of Burnout Syndrome and Its Three Dimensions in Dental Faculty Members of Azad Dental University in 2008. The Journal of Islamic Dental Association of IRAN (JIDA) 2013, 25(1):45-52. 
7. TORABI PARIZI M, ESKANDARIZADEH A, KARIMI AFSHAR M, ASADI SHEKAARI M, JANGJOO A: THE FREQUENCY OF JOB BURNOUT AMONG DENTISTS OF KERMAN CITY. HEALTH AND DEVELOPMENT JOURNAL 2015, 3(4):-.

8. Lee C-Y, Wu J-H, Du J-K: Work stress and occupational burnout among dental staff in a medical center. Journal of Dental Sciences 2019, 14:295-301.

9. Khatatbeh H, Pakai A, Pusztai D, Szunomár S, Fullér N, Szebeni GK, Siket A, Zrínyi M, Oláh A: Burnout and patient safety: A discriminant analysis of paediatric nurses by low to high managerial support. Nursing Open 2021, 8:982-989.

10. Slabšinskienè E, Gorelik A, Kavaliauskienè A, Zaborskis A: Burnout and Its Relationship with Demographic and Job-Related Variables among Dentists in Lithuania: A Cross-Sectional Study. International Journal of Environmental Research and Public Health 2021, 18(8):3968.

11. Rezai H, Mohseni Takalu MT, Zamani P, Heravi F: Relationship between temperament and stuttering severity in Persian speaking subjects with advanced stuttering. Journal of Islamic and Iranian Traditional Medicine 2014, 5(2):101-107.

12. Safari MA, KOUSHKI JAHROMI M, ZAR A: THE ROLE OF FOUR TEMPERAMENTS IN PREDICTING PHYSICAL ACTIVITY IN YOUNG MEN. SPORT PHYSIOLOGY \& MANAGEMENT INVESTIGATIONS 2017, 8(4):-.

13. MOHEBBI DEHNAVI Z, TORKMANNEJAD SABZEVARI M, RASTAGHI S, RAD M: THE RELATIONSHIP BETWEEN PREMENSTRUAL SYNDROME AND TYPE OF TEMPERAMENT IN HIGH SCHOOL STUDENTS. IRANIAN JOURNAL OF OBSTETRICS, GYNECOLOGY AND INFERTILITY 2017, 20(5):-.

14. TORKMANNEJAD SABZEVARI M, EFTEKHAR YAZDI M, RASTAGHI S, RAD M: THE RELATIONSHIP BETWEEN DIFFERENT TEMPERAMENTS AND POSTPARTUM DEPRESSION IN HEALTH CENTERS IN SABZEVAR, 2017. IRANIAN JOURNAL OF OBSTETRICS, GYNECOLOGY AND INFERTILITY 2018, 21(6 \#B00246):-

15. Banaee E, Pouladi S, Bahreini M, Tahmasebi R: Relationship between temperament and communication skills of nursing and midwifery student of Bushehr University. Journal of Islamic and Iranian Traditional Medicine 2019, 9(4):297-308.

16. Naghizadeh A, Salamat M, Hamzeian D, Akbari S, Rezaeizadeh H, Vaghasloo MA, Karbalaei R, Mirzaie M, Karimi M, Jafari M: IrGO: Iranian traditional medicine General Ontology and knowledge base. In: J Biomed Semantics. vol. 12; 2021: 9.

17. Kazemeini SK, Emtiazy M, Owlia F, Khani P: Causes of infertility in view of Iranian traditional medicine: A review. International journal of reproductive biomedicine 2017, 15(4):187-194.

18. Kulkarni S, Dagli N, Duraiswamy P, Desai H, Vyas H, Baroudi K: Stress and professional burnout among newly graduated dentists. Journal of International Society of Preventive \& Community Dentistry 2016, 6(6):535-541.

19. Choy HB, Wong MC: Occupational stress and burnout among Hong Kong dentists. Hong Kong medical journal = Xianggang yi xue za zhi 2017, 23(5):480-488. 
20. Basirat $\mathrm{M}$, kia s, malekshoar $\mathrm{m}$, saffarieh $\mathrm{m}$, javanshir b: Prevalence of Occupational Burnout and its Related Factors among Dentists in Semnan, Iran. Journal of Occupational Hygiene Engineering 2019, 6(2):45-51.

21. Moalemi S, Kavoosi Z, Beygi N, Deghan A, Karimi A, Parvizi MM: Evaluation of the Persian Version of Maslach Burnout Inventory-Human Services Survey among Iranian Nurses: Validity and Reliability. Galen Medical journal 2018, 7(1):995-.

22. SALMANNEZHAD H, MOJAHEDI M, EBADI A, MOZAFFARPUR SA, ALIPOOR A, SAGHEBI R, MONTAZERI A: DESIGN AND VALIDATION OF MIZAJ IDENTIFICATION QUESTIONNAIRE IN PERSIAN MEDICINE. IRANIAN RED CRESCENT MEDICAL JOURNAL (IRCMJ) 2018, 20(11):-.

23. Molina-Hernández J, Fernández-Estevan L, Montero J, González-García L: Work environment, job satisfaction and burnout among Spanish dentists: a cross-sectional study. BMC oral health 2021, 21(1):156.

24. Salvagioni DAJ, Melanda FN, Mesas AE, González AD, Gabani FL, Andrade SM: Physical, psychological and occupational consequences of job burnout: A systematic review of prospective studies. 2017, 12(10):e0185781.

25. Jaracz M, Rosiak I, Bertrand-Bucińska A, Jaskulski M, Nieżurawska J, Borkowska A: Affective temperament, job stress and professional burnout in nurses and civil servants. PloS one 2017, 12(6): 00176698.

26. Porto GG, Carneiro SC, Vasconcelos BC, Nascimento MM, Leal JL: Burnout syndrome in oral and maxillofacial surgeons: a critical analysis. International journal of oral and maxillofacial surgery 2014, 43(7):894-899.

27. BOLBOLIAN M, Mir Keshavarz M, SEFIDI F, Mir A: The prevalence of burnout syndrome among general dentists in Qazvin, Iran in 2017. JOURNAL OF CRANIOMAXILLOFACIAL RESEARCH 2018, 5(4):--

28. Shorofi SA, Karimzadeh M: Factors Associated with Burnout in Nursing Staff:A Review Article. Clinical Excellence 2015, 3(2):56-70.

29. Farokh-Gisour E, Hatamvand M: Investigation of Stress Level Among Dentistry Students, General Dentists, and Pediatric Dental Specialists During Performing Pediatric Dentistry in Kerman, Iran, in 2017. The open dentistry journal $2018,12: 631-637$.

30. Yang S, Liu D, Liu H, Zhang J, Duan Z: Relationship of work-family conflict, self-reported social support and job satisfaction to burnout syndrome among medical workers in southwest China: A cross-sectional study. PloS one 2017, 12(2):e0171679.

31. Chemali Z, Ezzeddine FL, Gelaye B, Dossett ML, Salameh J, Bizri M, Dubale B, Fricchione G: Burnout among healthcare providers in the complex environment of the Middle East: a systematic review. BMC Public Health 2019, 19(1):1337.

32. Khosravi M: Burnout among Iranian medical students: Prevalence and its relationship to personality dimensions and physical activity. European journal of translational myology 2021, 31(1). 
33. Heidari MA, Sargolzaei MS, Mastalizadeh H, Shahrakimoghadam E, Pahlevan Nasirabady A, Naderyanfar F: COMPARATIVE STUDY OF SELF-CARE IN DIABETIC PATIENTS WITH PERSONALITY TYPES A AND B. Nursing and Midwifery Journal 2020, 18(5):379-386.

34. Uchmanowicz I, Manulik S, Lomper K, Rozensztrauch A, Zborowska A, Kolasińska J, Rosińczuk J: Life satisfaction, job satisfaction, life orientation and occupational burnout among nurses and midwives in medical institutions in Poland: a cross-sectional study. BMJ open 2019, 9(1):e024296.

35. Abedi G, Molazadeh-Mahali QA, Mirzaian B, Nadi-Ghara A, Heidari-Gorji AM: The Effect of Personality Traits of Managers/Supervisor on Job Satisfaction of Medical Sciences University Staffs. Annals of medical and health sciences research 2016, 6(4):239-242.

36. Pérez-Fuentes MDC, Molero Jurado MDM: Burnout and Engagement: Personality Profiles in Nursing Professionals. 2019, 8(3).

37. Mozaffarpur SA, Mojahedi M, Saghebi R, Alipour A, Shirafkan H: The Relationship Between Mizaj and its indices in Persian Medicine. Advances in Integrative Medicine 2019, 6:S81.

38. YAZDANFAR A, DADRAS F, HOSSEINI YEKTA N: HUMAN TEMPERAMENTS CLASSIFICATION AND RELATED TENDENCIES TO ARCHITECTURE INDICES. JOURNAL OF NURSE AND PHYSICIAN WITHIN WAR 2015, 2(5):-. 